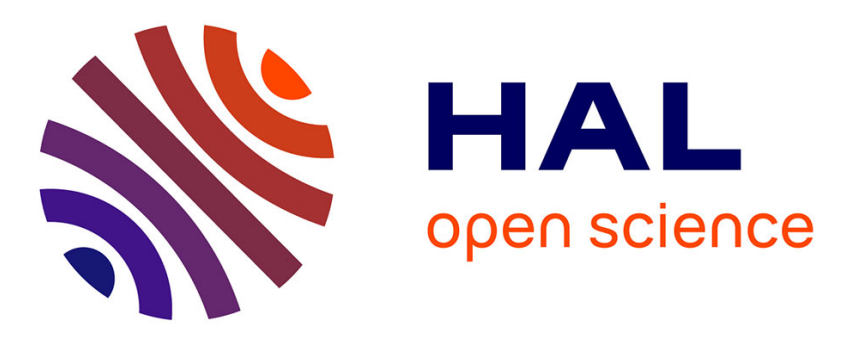

\title{
Coordination Complexes of P-Containing Polycyclic Aromatic Hydrocarbons: Optical Properties and Solid-State Supramolecular Assembly
}

François Riobé, Rózsa Szűcs, Christophe Lescop, Régis Réau, László Nyulászi, Pierre-Antoine Bouit, Muriel Hissler

\section{To cite this version:}

François Riobé, Rózsa Szűcs, Christophe Lescop, Régis Réau, László Nyulászi, et al.. Coordination Complexes of P-Containing Polycyclic Aromatic Hydrocarbons: Optical Properties and Solid-State Supramolecular Assembly. Organometallics, 2017, 36 (14), pp.2502-2511. 10.1021/acs.organomet.6b00715 . hal-01449086

HAL Id: hal-01449086

https://hal-univ-rennes1.archives-ouvertes.fr/hal-01449086

Submitted on 7 Feb 2017

HAL is a multi-disciplinary open access archive for the deposit and dissemination of scientific research documents, whether they are published or not. The documents may come from teaching and research institutions in France or abroad, or from public or private research centers.
L'archive ouverte pluridisciplinaire HAL, est destinée au dépôt et à la diffusion de documents scientifiques de niveau recherche, publiés ou non, émanant des établissements d'enseignement et de recherche français ou étrangers, des laboratoires publics ou privés. 


\title{
Coordination complexes of P-containing Polycyclic
}

\section{Aromatic Hydrocarbons: optical properties and}

\section{solid-state supramolecular assembly}

\author{
François Riobé,,${ }^{\dagger}$ Rózsa Szücs ${ }^{\dagger,}$ Christophe Lescop, ${ }^{\dagger}$ Régis Réau, ${ }^{\dagger}$ László Nyulászi, ${ }^{*}{ }^{+}$Pierre- \\ Antoine Bouit, ${ }^{* \dagger}$ Muriel Hissler* ${ }^{* \dagger}$ \\ †Institut des Sciences Chimiques de Rennes UMR 6226 CNRS - Université de Rennes 1, \\ Campus de Beaulieu, 263 avenue du Général Leclerc, 35042 Rennes France
}

${ }^{\sharp}$ Department of Inorganic and Analytical Chemistry, Budapest University of Technology and Economics, Szt. Gellert ter 4 H-1111 Budapest, Hungary

\begin{abstract}
A series of complexes including $\sigma^{3}, \lambda^{3}$-P-modified PAH as a ligand have been prepared showing that the ligand possesses a classical "phosphine like" reactivity. The use of different metals $(\operatorname{Pd}(\mathrm{II}), \mathrm{Cu}(\mathrm{I}), \operatorname{Re}(\mathrm{I}), \mathrm{Au}(\mathrm{I}))$ having different coordination number allows to tune the optical properties of the complexes, which is dominated basically by the electronic transitions of the ligand itself. The study of the solid state properties by mean of X-ray diffraction also shows that
\end{abstract}


the combination of coordination chemistry and $\pi$-stacking interactions between the PAH ligand allows to obtain a great diversity of solid state structures.

KEYWORDS: Polycyclic Aromatic Hydrocarbons, P-ligand, optical properties, supramolecular assembly

\section{INTRODUCTION}

Polycyclic Aromatic Hydrocarbons (PAHs) attract considerable attention due to their unique electronic properties making them appealing for applications in molecular electronics such as organic solar cells and field-effect transistors. ${ }^{1,2,3}$ Their unique properties stemming from the extended pi-conjugation within planar or curved backbones, are affected by the geometries (sizes, symmetries, boundaries and cores) and the electronics. Furthermore, the $\pi$-stacking ability of these compounds allows an efficient charge transport between the molecules. ${ }^{4}$ An original approach to tune the properties of the PAHs or to organize them in the solid state is to use them as ligands toward metal complexes and benefit both electronic and structural properties of the transition metals and the large organic $\pi$-system. In this regard, the first examples used the concepts of $\pi$-coordination of arene ligands toward transition metals. ${ }^{5}$ For example, the $\eta^{6}$ coordination of $\left.\left[\eta^{5}-\mathrm{C}_{5} \mathrm{Me}_{5}\right) \mathrm{Fe}(\mathrm{II})\right](\mathbf{A}$, Figure 1$), \mathrm{Cr}(\mathrm{CO})_{3}, \mathrm{Ru}(p-\mathrm{Cymene})$ or $\mathrm{Rh}(\mathrm{I})\left({ }^{i} \mathrm{Bu}_{3} \mathrm{P}\right)_{2}$ to PAHs of various size up to the hexa-peri-hexabenzocoronene were developed. ${ }^{6}$ This method allowed to introduce new redox properties directly linked to the nature of the metal. This strategy has also been successively extended to graphene layers and curved PAHs such as corannulene. ${ }^{7}$ The $\eta^{2}$ coordination of $\operatorname{Ag}(\mathrm{I})$ was also found to be an interesting approach to tune the properties of the PAHs. ${ }^{8}$ The crystallographic structure of the triple decker complex B (Figure 1), revealed both inter- and intramolecular $\pi$-stacking interactions between the PAHs ligands. ${ }^{8 a}$ This study 
nicely showed how the presence of the metal ion allows the modification of the solid-state structure of PAHs. All these strategies use the $\pi$-surface of the PAH to coordinate to the metal fragment. Another approach consists of grafting the metal fragment to the PAH through a $\sigma$ bond. This approach was used to link PAHs to Pt-acetylide (C, Figure 1), ferrocenyl, Ir-carbenes, Au-aryl fragments or bipyridine rhenium tricarbonyl. ${ }^{9}$ This strategy allowed to obtain new redox and photophysical properties linked to the presence of the metal such as phosphorescence. These strategies are based on the organometallic chemistry of PAHs. Recently, new synthetic methods allowed to prepare heteroatom-containing $\mathrm{PAHs}^{10}$ such as $\mathrm{N},{ }^{11} \mathrm{~B}^{12} \mathrm{~S}^{13}, \mathrm{O}^{14}$ or $\mathrm{P} .{ }^{15}$ In the case of $\mathrm{N}$ - or P-containing PAHs, the heteroatom has a crucial importance because it allows the use of its coordination ability to prepare new coordination complexes. In this field, the first step was made by Draper et al. who prepared $\mathrm{Ru}(\mathrm{II})$ (D, Figure 1), and $\mathrm{Pd}(\mathrm{II})$ complexes using their unprecedented N-containing heterosuperbenzene as a ligand. ${ }^{16}$ The authors showed that the presence of the metal allows new optical transitions (MLCT based) as well as new redox properties compared to the parent PAH. ${ }^{16 \mathrm{~b}, 17}$ Finally, a last method to prepare metal-containing PAHs relies on the extension of the $\mathrm{C}-\mathrm{sp}^{2}$ backbone around a metalloporphyrin ${ }^{18}$ or a metallophtalocyanine unit. ${ }^{19}$ For example, compound E (Figure 1) displays intense visible and near-IR absorption and a very low HOMO-LUMO gap. However, the exceptional electronic properties of the compound come more from the presence of the porphyrinic cycle than the presence of the metal. 


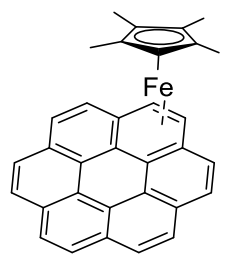

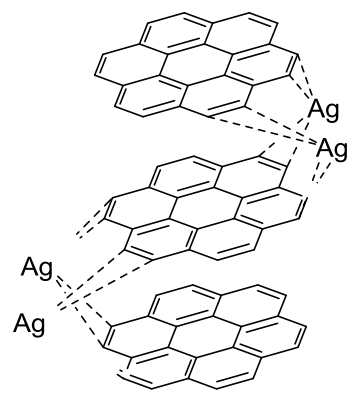

B

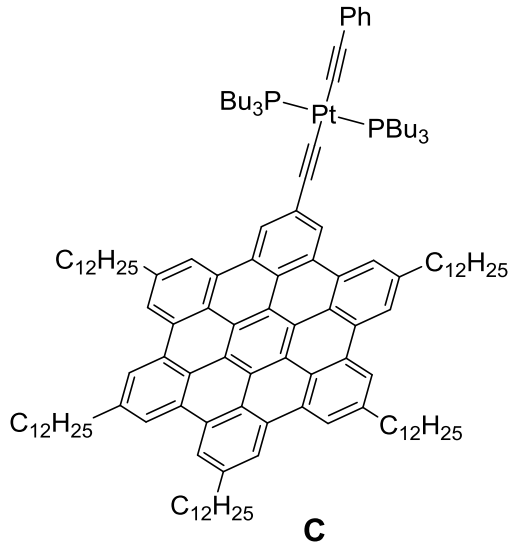

C

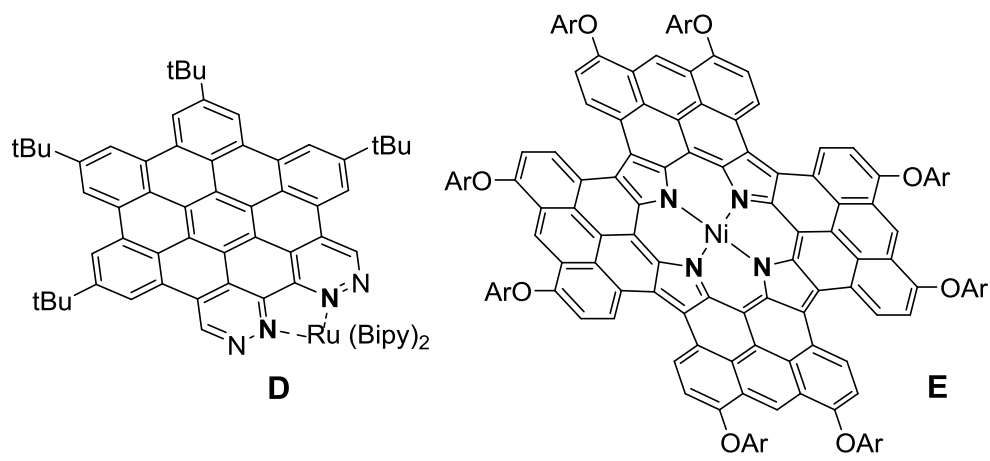

Figure 1. Examples of organometallic $(\mathbf{A}, \mathbf{B}, \mathbf{C})$ and coordination complexes (D, E) using PAHs as ligands (counterions have been omitted for clarity).

We recently synthesized a P-containing PAH (L1-2, Scheme 1) that showed a tunable HOMOLUMO gap using P-modification. ${ }^{15}$ For example, the corresponding (thio)oxidized derivative SL1 (Scheme 1) appeared to be an efficient emitter in the active layer of a white-emitting OLED. ${ }^{20}$ In the present article, we extend our strategy based on the use of P-containing ligands as 2-electrons donors toward transition metals. ${ }^{21}$ We show that the insertion of different metals $(\operatorname{Pd}(\mathrm{II}), \mathrm{Cu}(\mathrm{I}), \operatorname{Re}(\mathrm{I}), \mathrm{Au}(\mathrm{I}))$ having different coordination numbers allows to tune the optical properties of the complexes as has been evidenced by combined experimental and theoretical approaches. The study of the solid state properties by mean of X-ray diffraction also shows that the metal has a huge impact on the supramolecular organization. These results show how the 
insertion of a P-atom into the PAH backbone allows to tune both optical and supramolecular assembly using the coordination ability of the P-ligand.

\section{RESULT AND DISCUSSION}

Synthesis and Characterization. P-containing PAHs L1 and L2 (scheme 1) were synthesized according to our previously reported synthetic method. ${ }^{15,20}$ An appealing chemical property of these $\sigma^{3}, \lambda^{3}$-P-derivatives is their reactivity towards metal ions. Reaction of $\mathbf{L} \mathbf{1}$ with one equivalent of $\mathrm{AuCl}$ afforded complex AuL1 $\left({ }^{31} \mathrm{P}\right.$ NMR $\left.=+26.5 \mathrm{ppm}\right)$ in good yield (Scheme 1). ${ }^{15}$ The reaction of AuL1 with one equivalent of AgOTf, then with another equivalent of $\sigma^{3}, \lambda^{3}$ P-ligand $\mathbf{L 1}$ led to the formation of the complex $\mathbf{A u}(\mathbf{L} 1)_{2}\left({ }^{31} \mathrm{P}\right.$ NMR $\left.=+40.8 \mathrm{ppm}\right)$, composed of two PAHs assembled around $\mathrm{Au}(\mathrm{I})$ metal center (Scheme 1). The two gold complexes AuL1 and $\mathbf{A u}(\mathbf{L 1})_{2}$ were characterized by MS and X-ray diffraction. The coordination chemistry of this novel family of ligands is not limited to $\mathrm{Au}(\mathrm{I})$ chemistry. Indeed, we chose to investigate the coordination chemistry of these ligands towards $\mathrm{Pd}(\mathrm{II}), \mathrm{Cu}(\mathrm{I})$ and $\mathrm{Re}(\mathrm{I})$ ions since these metal ions exhibit different coordination geometries (square planar, tetrahedral and octahedral geometries, respectively) and can accommodate different numbers of PAH ligands in the coordination sphere. The reaction of $\mathbf{L 1 - 2}$ with $\mathrm{Cu}(\mathrm{I}), \mathrm{Pd}(\mathrm{II})$ or $\mathrm{Re}(\mathrm{I})$ precursors led to the formation of a cationic complex $\mathbf{C u}(\mathbf{L} 1)_{2}\left({ }^{31} \mathrm{P}\right.$ NMR $\left.=-2.9 \mathrm{ppm}\right)$ and neutral complexes $\mathbf{P d}(\mathbf{L} 2)_{2}$ $\left({ }^{31} \mathrm{P}\right.$ NMR $\left.=+28.6 \mathrm{ppm}\right)$ and $\operatorname{ReL1}\left({ }^{31} \mathrm{P}\right.$ NMR $\left.=+3.4 \mathrm{ppm}\right)($ Scheme 1$)$. The formation of the cationic complex $\mathbf{C u}(\mathbf{L 1})_{2}$ and the neutral complex $\mathbf{P d}(\mathbf{L} 2)_{2}$ results in the substitution of two acetonitrile ligands of $\left[\mathrm{Cu}\left(\mathrm{CH}_{3} \mathrm{CN}\right)_{4}\right] \mathrm{PF}_{6}$ and $\left[\mathrm{PdCl}_{2}\left(\mathrm{CH}_{3} \mathrm{CN}\right)_{2}\right]$ precursors by two ligands $\mathbf{L}$, respectively. For the complex $\mathbf{P d}(\mathbf{L} 2)_{2}$, the ${ }^{31} \mathrm{P}$ NMR spectrum revealed the presence of only one isomer. By comparison with the related bis-phosphole palladium complexes ${ }^{22}$ the chemical shift 
at $+28.6 \mathrm{ppm}$ can be attributed to a cis-configured complex. ${ }^{23}$ In the case of $\mathbf{C u}(\mathbf{L 1})_{2}$, two acetonitrile ligands remain coordinated on the $\mathrm{Cu}(\mathrm{I})$ ion, at least in the solid state. The steric hindrance at the metal center probably forbids the additional substitution of another acetonitrile ligand by the bulky PAH L1. The complex ReL1 was prepared by reacting the ligand $\mathbf{L} 1$ with $\mathrm{ReCl}(\mathrm{CO})_{5}$ in toluene at $80^{\circ} \mathrm{C}$ under argon. ${ }^{24}$ After purification, all these complexes were isolated with moderate yields (55-60\%) and were characterized by NMR, MS and X-ray diffraction.

The aromatic systems and the phosphole ring possess a tremendous variety of complexing modes $(\sigma \text { and/or } \eta \text {-complexes, Figure } 1)^{5-16,25}$ but here we have shown that $\sigma^{3}, \lambda^{3}$-Pcontaining PAHs L1-2 display the classical "phosphine like" reactivity not only toward (thio)oxidation and alkylation but also toward different metal centers, allowing the straightforward formation of unprecedented structures. 


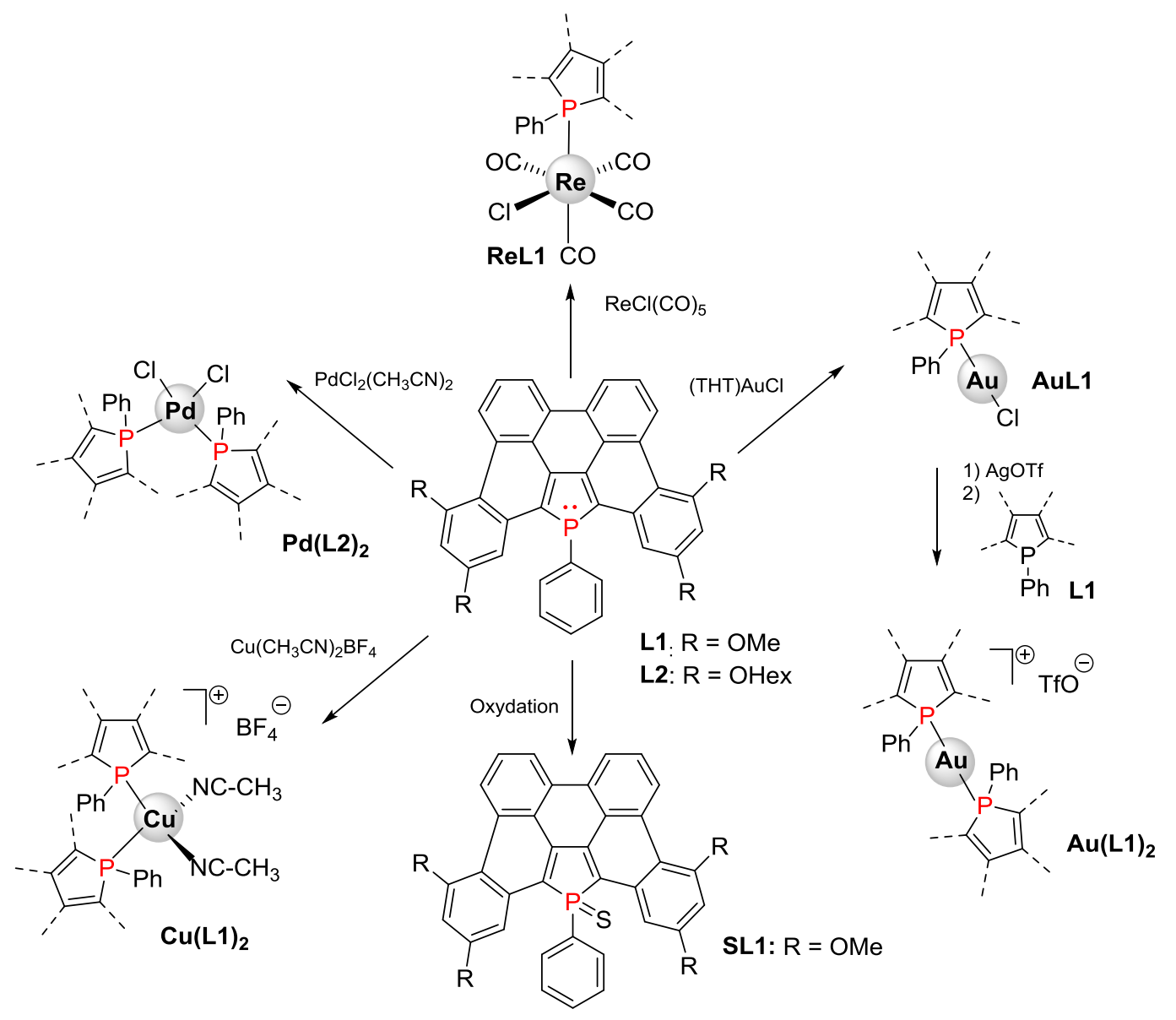

Scheme 1. Synthesis of coordination complexes using P-containing PAHs L1-2 as ligands.

X-ray Crystal Structure. The chemical structure of complexes ReL1, AuL1, Au(L1)2, and $\mathbf{C u}(\mathbf{L 1})_{2}$ were confirmed by X-ray diffraction studies performed on single crystals obtained by slow vapor diffusion of pentane into dichloromethane solutions. The crystal data and the experimental details are given in SI. Selected bonding parameters and angles of these complexes are summarized in Table 1.

The complexes ReL1 and AuL1 having one ligand L1 in their coordination sphere present similar metric data for the ligand $\mathbf{L} \mathbf{1}$ which remain basically unchanged compared to those observed in the solid state structure of the purely organic compound. ${ }^{15}$ Effectively, the 
coordinated P-center, lying in the $\mathrm{sp}^{2}-\mathrm{C}$ plane, has a pyramidal shape with usual valence angles and the C-P and C-C bond lengths are similar to those reported for P-based PAHs (see Table 1). ${ }^{20}$ Furthermore, the PAH fragment (including the P-center) is almost planar. The difference lies in the solid state organization of these complexes since they do not crystalize in the same space group.

The $\mathrm{Au}(\mathrm{I})$ complex, AuL1, crystallizes in the $C 2 / c$ space group of the monoclinic system (Table 1 and S1). The asymmetric unit contains a neutral complex AuL1 (Figure 2) and is completed by one $\mathrm{CH}_{2} \mathrm{Cl}_{2}$ solvent molecule that does not show short contact interactions with the complex AuL1. In this derivative, the P-center of the ligand $\mathbf{L}$ acts as expected, as a two-electron donor toward the $\mathrm{Au}(\mathrm{I})$ metal center $(\mathrm{d}(\mathrm{P}-\mathrm{Au}), 2.222(2) \AA)$ and the $\mathrm{P}-\mathrm{Au}-\mathrm{Cl}$ fragment is almost linear (P-Au-Cl, 173.07(12) $)^{\circ}$. The coordinated P-center has a distorted tetrahedral geometry (angles range between ca. $92.5^{\circ}$ for the endocyclic C-P-C angle) and the PAH fragment (including the P-center) is almost planar (maximum deviation for the mean plane, ca. $0.15 \AA$ ).

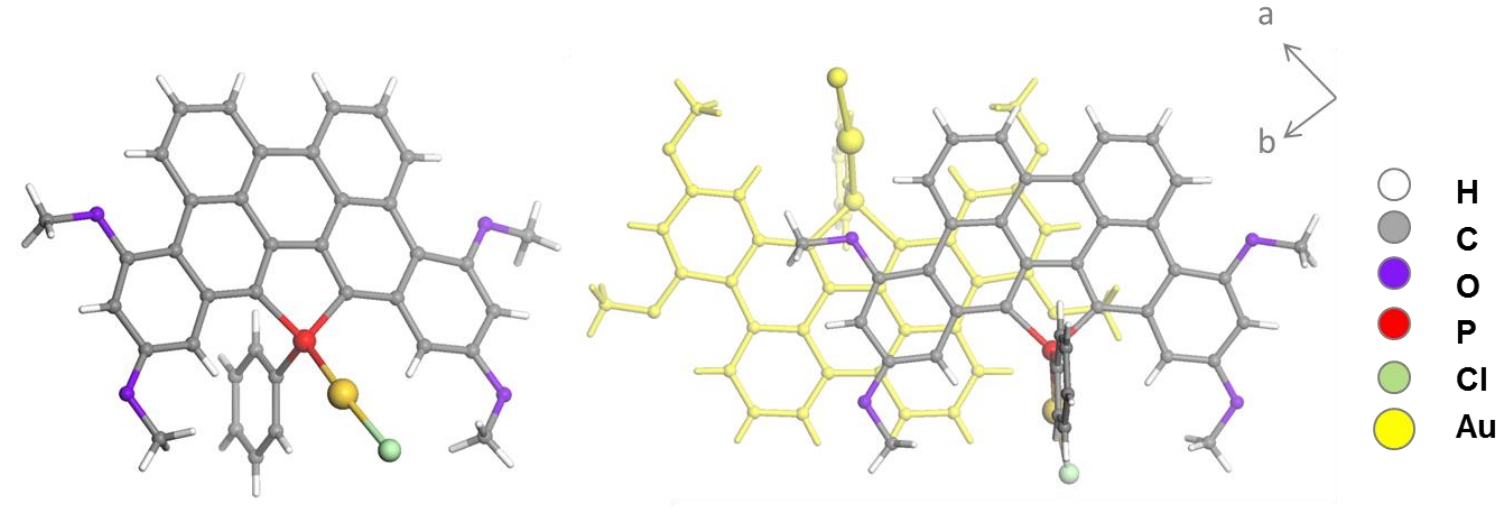

Figure 2: X-ray crystallographic structure of AuL1 with the view of the discrete dimers observed in the packing. 
Derivative ReL1 crystallizes in the $P-1$ space group of the triclinic system (Table 1 and S1). The asymmetric unit contains a neutral complex $\mathbf{R e L 1}$ (Figure 3) and included $1.5 \mathrm{CH}_{2} \mathrm{Cl}_{2}$ solvent molecules complete the asymmetric unit and do not show any short contact interaction with the complex ReL1. The coordination sphere of the $\operatorname{Re}(\mathrm{I})$ metal center is distorted octahedral with the coordinated chloride and phosphorus atoms in cis-positions. The P-Re bond length is classical for a $\sigma^{3}-\mathrm{P}$ center acting as two electron donor on a $\operatorname{Re}(\mathrm{I})$ ion $(\mathrm{d}(\mathrm{P}-\mathrm{Re}), 2.4999(16) \AA)$ and the polyaromatic fragment (including the P-center) presents a slight deviation to the planarity (maximum deviation for the mean plane including the P-center, ca. $0.37 \AA$ ) and a dihedral angle of ca. $7.1^{\circ}$ between the mean planes of the two lateral phenanthryl subunits.
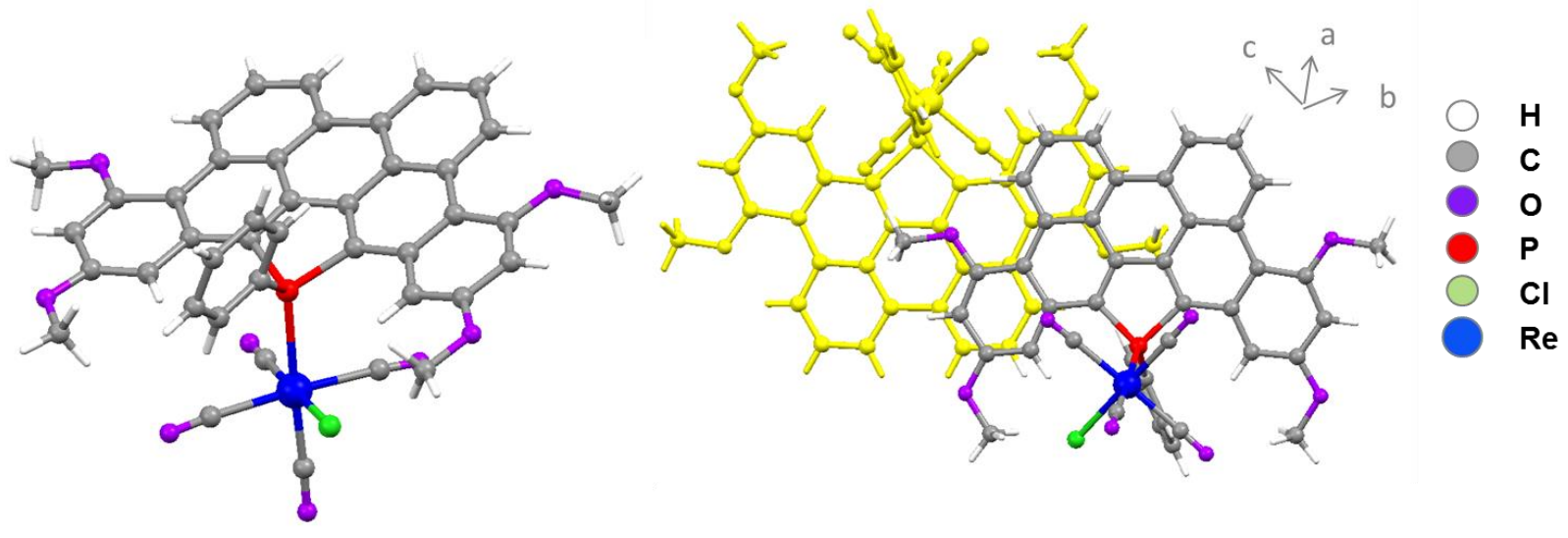

Figure 3: X-ray crystallographic structure of ReL1 with the view of the discrete dimers observed in the packing.

The crystal packing of complexes AuL1 and ReL1 shows that the complexes form infinite columns (Figure 4) due to $\pi-\pi$ intermolecular interactions evidenced by a close packing (short contact distances ca. 3.4-3.5 $\AA$ ) between the two planar polyaromatic fragments. Within these columns, head-to-tail dimers are observed with a large overlay of the two interacting polyaromatic fragments (Figure 2 and 3). It can be noticed that these $\pi$ - $\pi$ interactions are less 
efficient in the case of the $\operatorname{ReL1}$ complex due to the presence of large $\operatorname{Re}(\mathrm{CO})_{4} \mathrm{Cl}$ fragment hindering an efficient stacking between PAH ligands. Nevertheless, ReL1 complex dimers, in turn, stack on each other via weaker $\pi-\pi$ contacts affording, once again, an infinite $\pi$ stacked columnar structure (Figure 4). Note that no Au-Au interactions are observed in the case of AuL1.
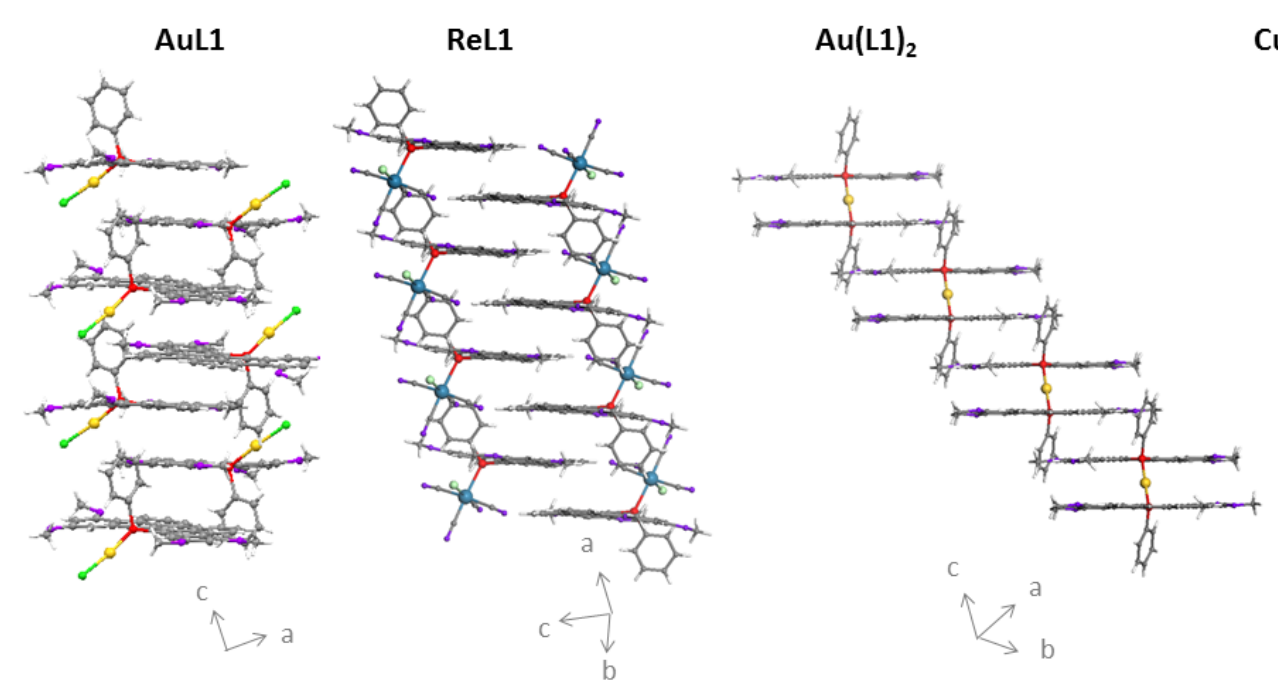

$\mathrm{Cu}(\mathrm{L1})_{2}$

Figure 4: View of the infinite columns observed in the packing for complex AuL1, ReL1, $\mathrm{Au}(\mathrm{L1})_{2}$ and $\mathrm{Cu}(\mathrm{L1})_{2}$.

The complexes $\mathbf{A u}(\mathbf{L 1})_{2}, \quad \mathbf{P d}(\mathbf{L} 2)_{2}{ }^{23}$ and $\mathbf{C u}(\mathbf{L} 1)_{2}$ having 2 PAH ligands in the coordination sphere crystallize in the same space group $P$ - 1 . Nevertheless, the different coordination sphere and coordination number of the metal ions allow different organization of the 2 ligands around the metal center and different solid state organization.

As previously reported, derivative $\mathbf{A u}(\mathbf{L} \mathbf{1})_{2}$ crystallizes in the $P-1$ space group of the triclinic system (Table 1 and S1). The asymmetric unit contains a complex $\mathbf{A u}(\mathbf{L} 1)_{2}$ resulting of the coordination of two ligands $\mathbf{L 1}$ on a $\mathrm{Au}(\mathrm{I})$ metal center (Figure 5). One $\mathrm{CF}_{3} \mathrm{SO}_{3}{ }^{-}$triflate 
counterion and three $\mathrm{CH}_{2} \mathrm{Cl}_{2}$ solvent molecules that do not show short contact interactions with the complex $\mathbf{A u}(\mathbf{L 1})_{2}$ complete the asymmetric unit. The $\mathrm{Au}(\mathrm{I})$ metal ion is located on the inversion center related with the $P-1$ space group and therefore its coordination geometry is strictly linear in this solid state structure. The two ligands L1 are symmetrically equivalent and form with the $\mathrm{Au}(\mathrm{I})$ metal center a stair like structure avoiding intramolecular $\pi-\pi$ interactions. The P-Au distance (d(P-Au), 2.3037(11) $\AA$ ) is slightly longer in the derivative Au(L1)2 compared to the derivative AuL1 which could be anticipated as a consequence of the formal replacement of the negatively charged $\mathrm{Cl}^{-}$ligand by a second equivalent of neutral ligand $\mathbf{L 1}$. As observed for the complex AuL1, metric parameters centered on the ligands L1 are mostly comparable with those of the P-ligand (maximum deviation for the mean plane including the Pcenter, ca. $0.08 \AA$ ). The coordinated P-centers bear a distorted tetrahedral geometry (angles range between ca. $92.6^{\circ}$ for the endocyclic C-P-C). Finally, in the crystal packing, infinite columns of molecules are observed due to intermolecular $\pi-\pi$ interactions (intermolecular contacts, ca. 3.5 $\AA$ ) involving the peripheral unsaturated rings of the PAH core of the ligands L1 (Figure 4,5). Note that as no intramolecular $\pi-\pi$ interactions occur between the two ligands L1 within the molecular structure of $\mathbf{A u}(\mathbf{L 1})_{2}$ (Figure 5), likewise no infinite network of pure $\pi-\pi$ interactions are formed along such columnar stacked arrays. Again, no Au-Au interactions are observed similarly to the case of AuL1. This supramolecular structure represents however a nice example of combination of coordination chemistry and $\pi-\pi$ interactions to afford organized structures. 


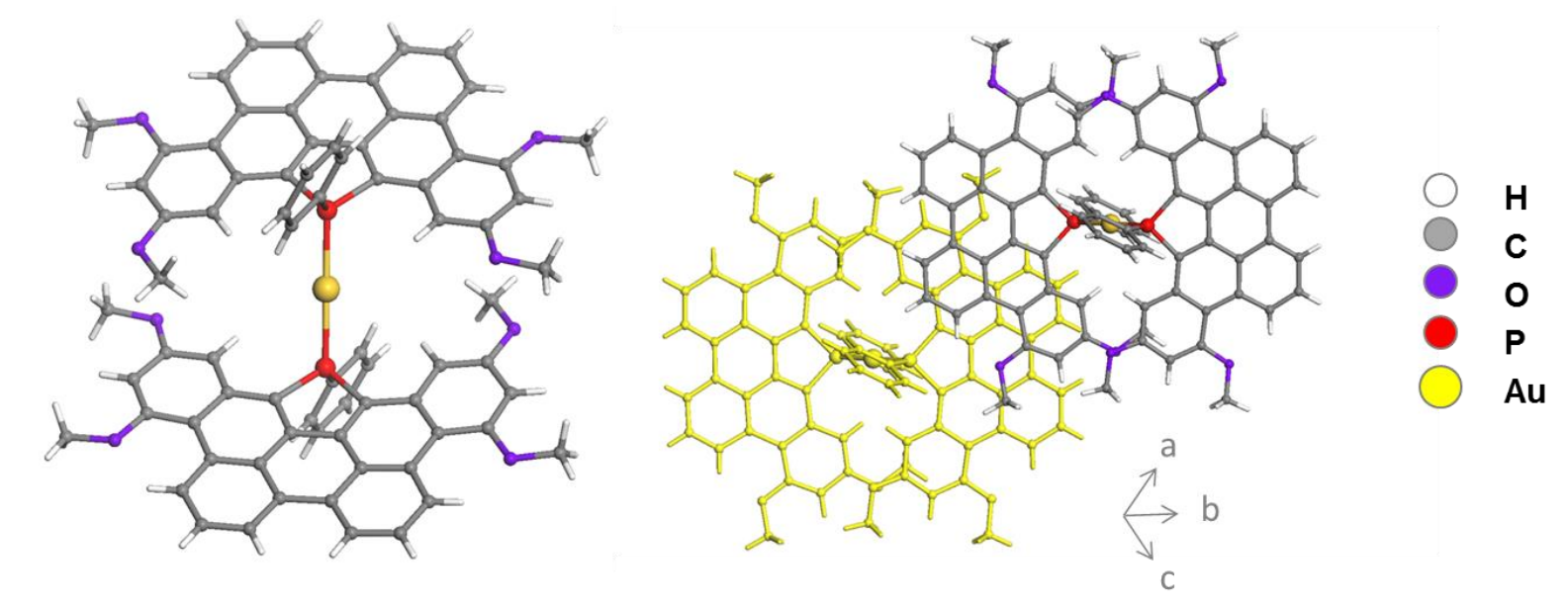

Figure 5: X-ray crystallographic structure of $\mathbf{A u}(\mathbf{L 1})_{2}$ with the view of the discrete dimers observed in the packing.

Derivative $\mathbf{C u}(\mathbf{L} 1)_{2}$ crystallizes in the $P-1$ space group of the triclinic system (Table 1). The asymmetric unit contains the monocationic complex $\mathbf{C u}(\mathbf{L 1})_{2}$ (Figure 6), a $\mathrm{BF}_{4}{ }^{-}$counterion and four $\mathrm{CH}_{2} \mathrm{Cl}_{2}$ solvent molecules, that do not show short contact interactions with the complex $\mathrm{Cu}(\mathbf{L 1})_{2}$. The $\mathrm{Cu}(\mathrm{I})$ metal center has a distorted tetrahedral geometry (angles range between $95.97(11)^{\circ}$ for the $\mathrm{N}-\mathrm{Cu}-\mathrm{N}$ angle and $113.87(4)^{\circ}$ for the $\mathrm{P}-\mathrm{Cu}-\mathrm{P}$ angle). The $\mathrm{P}-\mathrm{Cu}$ bond lengths are classical for a phosphine $\sigma^{3}-\mathrm{P}$ center acting as two electron donor on a $\mathrm{Cu}(\mathrm{I})$ metal center (d(P-Cu), 2.2524(11) $̊$ and 2.2569(11) $)$. Metric parameters observed for the two equivalents of the ligand $\mathbf{L} 1$ coordinated on the $\mathrm{Cu}(\mathrm{I})$ ion are mostly similar to those of the free ligand. This indicates that, as observed for the coordination on $\mathrm{Au}(\mathrm{I})$ center, coordination of the P-center on $\mathrm{Cu}(\mathrm{I})$ does not induce a noticeable modification of the structure of the ligand L1. The coordinated P-centers in this complex have a distorted tetrahedral geometry. The $\pi$-surface of one of the PAH L1 is almost planar (maximum deviation for the mean plane including the Pcenter, ca. $0.09 \AA$ ) but the second ligand bears a larger deviation of planarity (maximum deviation for the mean plane including the P-center, ca. $0.65 \AA$ ) with a dihedral angle of ca. $5.4^{\circ}$ 
between the mean planes of the two lateral phenantryl subunits of the PAH core. The orientation of the two ligands $\mathbf{L} \mathbf{1}$ coordinated on the distorted tetrahedral metal center (angle of $47^{\circ}$ ) results in the location of the $\pi$-surfaces of these ligands in a close proximity (Figure 6). Short contact interactions (ca. 3.2-3.3 $\AA$ ) revealing intramolecular $\pi-\pi$ interactions are observed along large portions of the $\pi$-surfaces while the mean planes of the polyaromatic cores of each PAH L1 are almost parallel (interplanar angle, ca. 5.3 ${ }^{\circ}$ ). As a consequence, the exocylic P-Ph moieties of each of the ligands are oriented outward to the central $\mathrm{Cu}(\mathrm{I})$ metal center. As observed in the case of the complex $\mathbf{P d}(\mathbf{L 2})_{2}$, the coordination of two PAH L1-2 on a metal center allows to organize two PAHs involved in intramolecular $\pi-\pi$ interactions. In the crystal packing, complexes $\mathbf{C u}(\mathbf{L 1})_{2}$ stack on each other with strong intermolecular $\pi-\pi$ interaction involving large portions of the $\pi$-surfaces. As a result, infinite columnar $\pi$-stacked networks are formed (Figure 4).
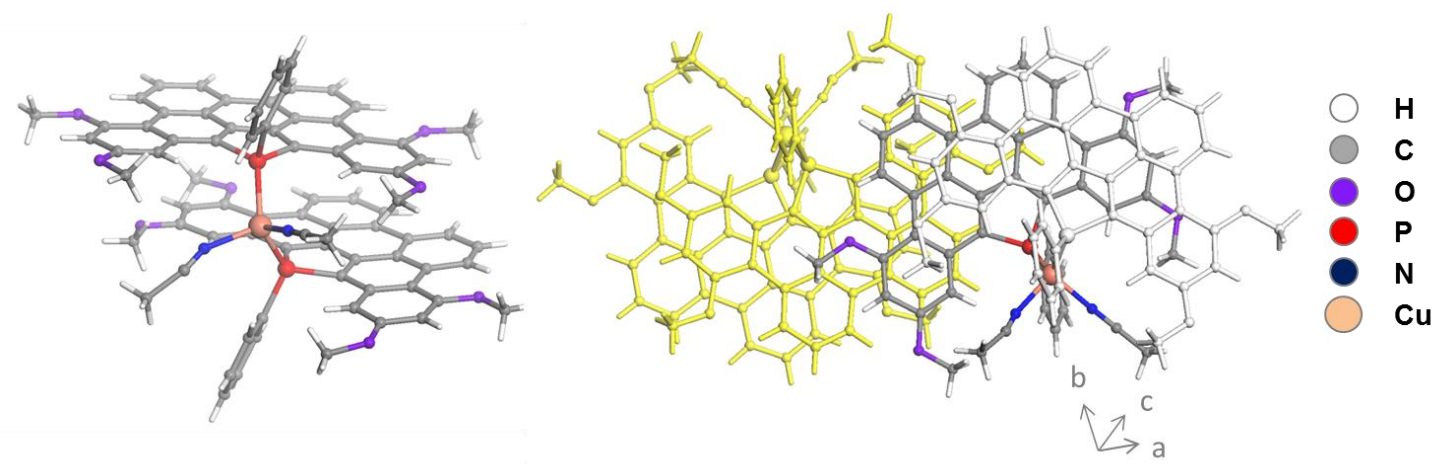

Figure 6: X-ray crystallographic structure of $\mathbf{C u}(\mathbf{L 1})_{2}$ with the view of the discrete dimers observed in the packing.

These examples show how coordination chemistry allows to tune supramolecular interactions between PAHs in the solid state. These interactions can be intramolecular, in the coordination 
sphere of the metal (compound $\mathbf{C u}(\mathbf{L 1})_{2}$ and $\left.\mathbf{P d}(\mathbf{L} 2)_{2}\right)$. Nevertheless, intermolecular interactions can also take place due to the $\pi$-stacking ability of the PAH ligand (compounds AuL1, ReL2, $\mathrm{Au}(\mathrm{L1})_{2}$ and $\left.\mathrm{Cu}(\mathrm{L1})_{2}\right)$. This property is very appealing considering the potential of this family of compounds for optoelectronic applications. Hence, using the same PAH based ligand, a great diversity of solid state structures can be obtained only by modification of the metallic ion. This unique property validates the strategy of inserting a coordinating atom such as P into a PAH.

Table 1. Selected Bond Distances $(\AA)$ and Angles (deg) for $A u L_{1}, \operatorname{ReL}_{1}, A u\left(L_{1}\right)_{2}$, and $\mathrm{Cu}\left(\mathrm{L}_{1}\right)_{2}$ and the reference compound $\mathrm{F}$ with Estimated Standard Deviations in Parentheses

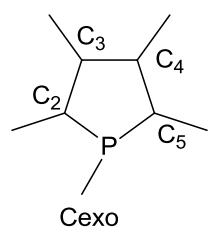

\begin{tabular}{|c|c|c|c|c|c|}
\hline Compounds & Au L1 & $\operatorname{Re} L 1$ & $\operatorname{Au}(\mathbf{L} 1)_{2}{ }^{b}$ & $\mathrm{Cu}(\mathrm{L1})_{2}$ & SL1 $^{b}$ \\
\hline $\mathrm{P}-\mathrm{C}_{2}$ & $1.810(9)$ & $1.829(5)$ & $1.805(3)$ & $\begin{array}{l}1.821(3) / \\
1.828(3)^{\mathrm{a}}\end{array}$ & $1.808(4)$ \\
\hline $\mathrm{P}-\mathrm{C}_{5}$ & $1.823(9)$ & $1.832(6)$ & $1.825(3)$ & $\begin{array}{c}1.830(3) / \\
1.816(3)\end{array}$ & $1.815(4)$ \\
\hline $\mathrm{C}_{2}-\mathrm{C}_{3}$ & $1.376(12)$ & $1.365(8)$ & $1.367(4)$ & $\begin{array}{c}1.370(4) / \\
1.355(5)\end{array}$ & $1.366(6)$ \\
\hline $\mathrm{C}_{3}-\mathrm{C}_{4}$ & $1.452(11)$ & $1.447(8))$ & $1.450(4)$ & $\begin{array}{c}1.445(5) / \\
1.447(4)\end{array}$ & $1.452(6)$ \\
\hline $\mathrm{C}_{4}-\mathrm{C}_{5}$ & $1.379(12)$ & $1.359(7)$ & $1.361(4)$ & $\begin{array}{c}1.365(5) / \\
1.359(5)\end{array}$ & $1.351(6)$ \\
\hline P-C $\mathrm{C}_{\mathrm{exo}}$ & $1.829(10)$ & $1.808(6)$ & $1.815(3)$ & $\begin{array}{l}1.838(3) / \\
1.828(3)\end{array}$ & $1.817(5)$ \\
\hline P-M & $2.222(2)$ & $2.4999(16)$ & $2.3037(11)$ & $\begin{array}{l}2.2524(11) / \\
2.2569(11)\end{array}$ & - \\
\hline $\mathrm{C}_{2}-\mathrm{P}-\mathrm{C}_{5}$ & $92.5(4)$ & 91.1(3) & $92.62(13)$ & $\begin{array}{c}91.22(15) / \\
90.91(15)\end{array}$ & $92.2(2)$ \\
\hline C2-P-Сexo & 105.1(4) & $105.6(2)$ & $107.9(4)$ & $\begin{array}{c}105.50(15) \\
/\end{array}$ & $103.6(2)$ \\
\hline
\end{tabular}


$108.57(14)$

\begin{tabular}{|c|c|c|c|c|}
\hline C5-P-Cexo & 103.4(4) & $108.5(3)$ & 108.6(3) & $\begin{array}{c}107.07(14) \\
/ \\
105.47(15)\end{array}$ \\
\hline
\end{tabular}

Electronic Absorption spectra and calculations. To evaluate the effect of the metal on the electronic properties of the compounds, the optical properties of complex AuL1, ReL1, $\mathbf{A u}(\mathbf{L 1})_{2}, \mathbf{C u}(\mathbf{L 1})_{2}$ and $\mathbf{P d}(\mathbf{L} 2)_{2}$ were investigated by UV-Vis absorption in diluted $\mathrm{CH}_{2} \mathrm{Cl}_{2}$ solution. As previously reported, the UV-Vis absorption spectrum of $\mathbf{L} \mathbf{1}$ displays a $\pi-\pi^{*}$ transition with classical PAH vibrational fine structures in the visible range $\left(\lambda_{\max }=472 \mathrm{~nm}\right.$, see Table 2, Figure 7). ${ }^{15}$ For AuL1 and ReL1 complexes, this absorption band with similar shape is red-shifted $(\Delta \lambda=20-40 \mathrm{~nm})$ due to the Lewis acid character of the metal ions. This trend is similar to the effect of oxidation (or thio-oxidation) of the P-center that was previously observed for both P-containing PAHs and phosphole oligomers. ${ }^{15,26}$ This effect stabilizes the LUMO to a larger extent than the HOMO for the gold derivative (Figure 8), the latter having a nodal plane right at the phosphorus atom bound to the metal center. ${ }^{15}$ In case of the ReL1 complex, the HOMO-LUMO difference remains virtually unaltered even if the HOMO contains some Re d orbital participation (Figure 8). Nevertheless, the Frontier MO-s of each complexes are located basically at the ligand, the orbitals of the metal atoms have mainly some perturbing effect. Our TD DFT calculations revealed that the lowest energy transitions are indeed basically the HOMOLUMO excitations (see Supporting Information) for both complexes AuL1 and ReL1, and these transitions are energetically well separated from the rest of the excitations. Furthermore, the B3LYP/def2-TZVP calculated vertical excitation energies match favorably with the observed 
band maxima positions, showing a smaller bathochromic shift for the Re than for the Au complex (Figure 7 and 8$)^{27}$

Likewise the orbitals of the $\mathrm{ML}_{2}$ type complexes behave similarly, HOMO, HOMO-1 and LUMO, LUMO+1 (Figure S8 in the Supporting Information) are composed from the HOMOs and LUMOs of the two ligands, giving rise altogether two pairs of occupied and two pairs of unoccupied orbitals. The absorption of the $\mathrm{ML}_{2}$ type complexes is shifted somewhat in the bathochromic direction in comparison with ML (Figure 7). The PAH vibronic fine structure, can also be recognized, however, this feature is more diffuse and the bands are also getting broader, especially in case of the Pd derivative, where even a new shoulder emerges at the low energy side. The TD-DFT calculations predict four close lying transitions, which involve the admixture of the excitations from the HOMO-1 and HOMO to the LUMO and LUMO+1 orbitals as shown in Figure 7. The numerical agreement between the calculated and the experimental results is the best in case of $\mathbf{P d}(\mathbf{L} 2)_{2}$. Since the X-ray structure of $\mathbf{P d}(\mathbf{L} 2)_{2}$ was of poor quality, we have optimized the structure of Pd(L1) $)_{2}$, at the M06-2X/LANL2DZ and at the $\omega$ B97X-D/LANL2DZ levels since these functionals account for dispersion effects, which is of high importance for $\pi$ stacked systems. The optimized structure was basically identical to that obtained by X-ray crystallography. ${ }^{28}$ Thus, we have decided to use for the TD DFT calculations the geometry obtained by X-ray crystallography, but using the smaller L1 ligand instead of the experimentally investigated L2. Since $\mathbf{L 1}$ and $\mathbf{L 2}$ have the same absorption band maxima - see Table 2 - this simplification has a minor effect only. As an apparent consequence of the rather strong intramolecular $\pi$-stacking between the ligands of $\mathbf{P d}(\mathbf{L} 2)_{2}$, the four excitations are splitted in this case significantly, and accordingly the TD-DFT calculations predicts two low-energy and medium intensity transitions at 578 and $573 \mathrm{~nm}$. In accordance, with the shoulder at $578 \mathrm{~nm}$ on 
the low energy side of the broad band with a maximum at $510 \mathrm{~nm}$, which in turn is in reasonable agreement with the most intense transition for $\mathbf{P d}(\mathbf{L 2})_{2}$ predicted at $527 \mathrm{~nm}$. Complexes $\mathbf{A u}(\mathbf{L 1})_{2}$ and $\mathbf{C u}(\mathbf{L 1})_{2}$ neither exhibit the low energy spectral feature, nor have low energy predicted transition energy. In these complexes the two ligands are rotated away from each other. In order to test if the $\pi$-stacking is responsible for the low energy feature in the spectrum, we have carried out TD DFT calculations on $\mathbf{C u}(\mathbf{L 1})_{2}$ with the two L1 ligands optimized at "cis" and "trans" position (the optimized geometries are presented in the Supporting Information). With the ligands in trans position the B3LYP/def2-cc-PVTZ//B3LYP/6-31G* calculations predict the four transition energies at 541, 530, 510 and $509 \mathrm{~nm}$, in case of the "cis" structure the vertical excitation energies are at 596,578, 501 and $500 \mathrm{~nm}$, showing that the splitting of the excitation energies is related to the $\pi$-stacked "cis" arrangement of the two ligands. This finding gives a further support to the X-ray structural arrangement of $\mathbf{P d}(\mathbf{L 2})_{2}$. Altogether, these tunable optical properties depending on the nature of the metal shows the pertinence of introducing a $\mathrm{P}$-atom in a PAH backbone in order to take advantage of its coordination ability to modify its electronic properties.

Table 2. UV-vis absorption data recorded in diluted DCM solutions. $\lambda_{\max }$ and $\lambda_{\text {vert }}$ (in $\mathrm{nm}$ ) refer to the measured maximum and the B3LP/def2-TZVP calculated first vertical excitation energy, respectively

$\begin{array}{lccccccc}\text { Compounds } & \text { L1 } & \text { L2 } & \text { AuL1 } & \operatorname{ReL1} & \operatorname{Au}(\mathbf{L 1})_{2}{ }^{\mathrm{b}} & \mathbf{C u}(\mathbf{L 1})_{2} & \operatorname{Pd}_{(\mathbf{L} 2)_{2}} \\ \lambda_{\max }(\mathrm{nm}) & 472 & 472 & 509 & 494 & 516 & 502 & 510\end{array}$




$\begin{array}{llllllll}\begin{array}{c}\text { FWHM } \\ \left(\mathrm{cm}^{-1}\right)\end{array} & 3790 & 3800 & 3780 & 3533 & 5135 & 5390 & - \\ & & & & & & & \\ & & & & & & & \\ & & & & & & & \\ \lambda_{\text {vert }}(\mathrm{nm}) & 479 & - & 512 & 482 & 529 & 534 & \end{array}$

$(578,573)$
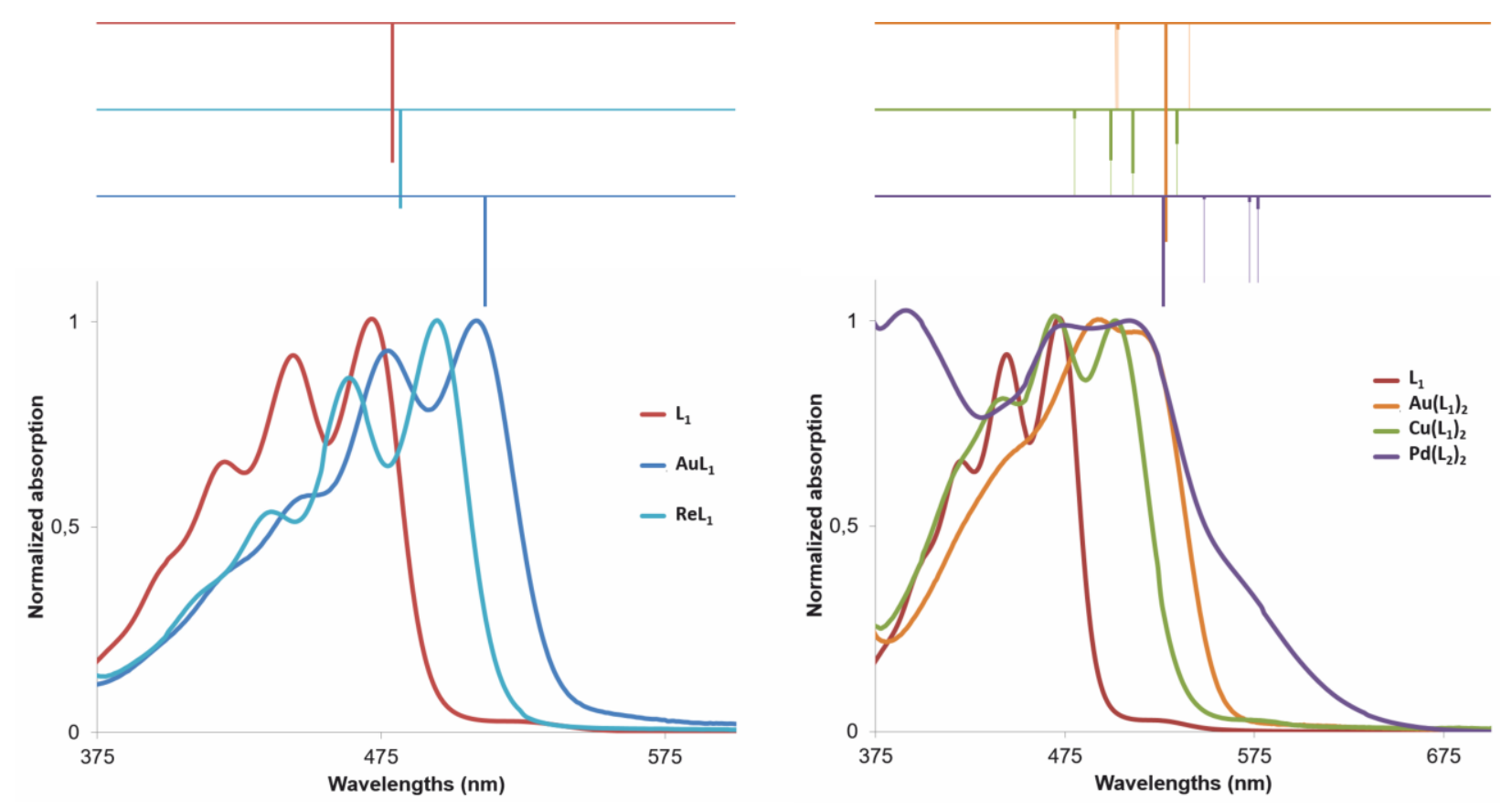

Figure 7: Absorption spectra of compounds L1, AuL1, ReL1, Au(L1) $)_{2}, \mathbf{C u}(\mathbf{L 1})_{2}$ and Pd(L2) in $\mathrm{CH}_{2} \mathrm{Cl}_{2}\left(10^{-5} \mathrm{M}\right)$. The TD DFT computed vertical excitation energies are presented above the experimental spectra. The size of the peaks representing the excitation energies is proportional to the calculated oscillator strength. 


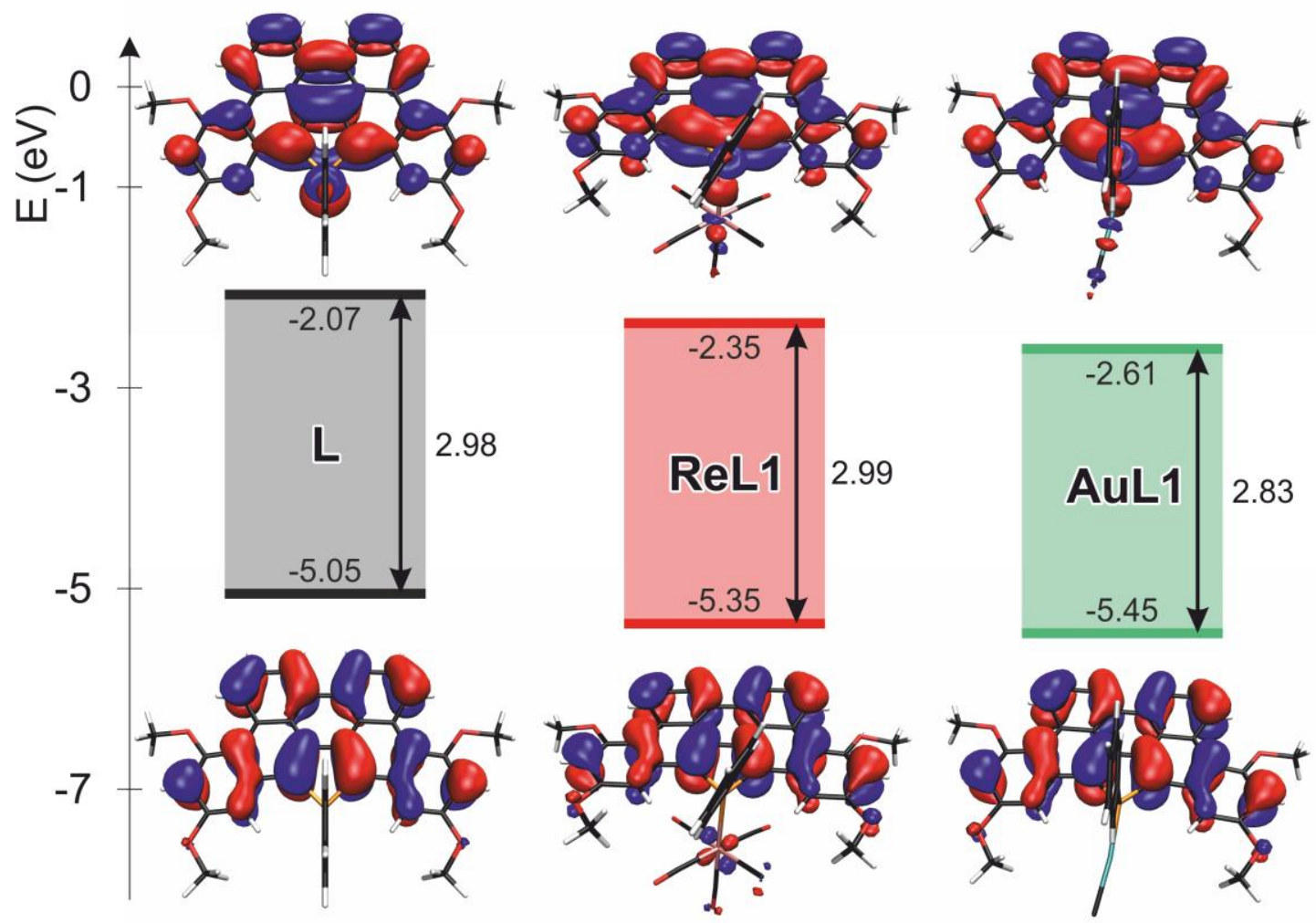

Figure 8: B3LYP/def2-tZVP//X-ray frontier MOs for L, ReL1 and AuL1. CONCLUSION

In conclusion, we demonstrated that $\sigma^{3}, \lambda^{3}$-P-modified PAHs possess the classical "phosphine like" reactivity toward different metal centers allowing the preparation of five new complexes having specific absorption properties. The combination of coordination chemistry and $\pi$-stacking interactions allows to obtain a great diversity of solid state structures as evidenced by the X-ray diffraction studies. In some cases, infinite $\pi$-stacked columns were observed. Furthermore, new solid state organization of phosphole-based PAHs can be envisaged since the phosphole ring possesses a tremendous variety of complexing modes ( $\sigma$ and $\eta$ coordination modes). ${ }^{25}$ This property is unusual for PAH compounds and is directly linked to the presence of the heteroatom into the $2 \mathrm{D} \pi$-conjugated system. Considering the potential of P-containing PAHs for opto- 
electronic applications, this molecular engineering based on coordination chemistry might lead to new promising applications in this field. ${ }^{29}$

\section{EXPERIMENTAL SECTION, CALCULATIONS}

Chemicals and instrumentations. All experiments were performed under an atmosphere of dry argon using standard Schlenk techniques. Commercially available reagents were used as received without further purification. Solvents were freshly purified using MBRAUN SPS-800 drying

columns. ${ }^{1} \mathrm{H},{ }^{13} \mathrm{C}$, and ${ }^{31} \mathrm{P}$ NMR spectra were recorded on a Bruker AM300, AM400. ${ }^{1} \mathrm{H}$ and ${ }^{13} \mathrm{C}$ NMR chemical shifts were reported in parts per million (ppm) relative to $\mathrm{Me}_{4} \mathrm{Si}$ as external standard. High-resolution mass spectra were obtained on a Varian MAT 311 or ZabSpec TOF Micromass instrument at CRMPO, University of Rennes 1. Compounds L1-2, AuL1 and $\mathbf{A u}(\mathbf{L 1})_{2}$ were synthesized according to published procedure. ${ }^{15,20}$ UV-Visible spectra were recorded at room temperature on a VARIAN Cary 5000 spectrophotometer.

\section{Synthesis.}

Cu(L1) 2. L1 (23 mg, $0.04 \mathrm{mmol}$, 1 eq.) was dissolved in $20 \mathrm{~mL}$ of dichloromethane. $\mathrm{Cu}\left(\mathrm{CH}_{3} \mathrm{CN}\right)_{2} \mathrm{BF}_{4}(0.04 \mathrm{mmol}, 0.5$ eq. $)$ was then added. The solution was stirred at $\mathrm{RT}$ for $15 \mathrm{~min}$ then the solvent was evaporated and the crude product was washed with pentane to afford $\mathbf{C u}(\mathbf{L 1})_{2}$ as a red solid (50\%). ${ }^{1} \mathrm{H}$ NMR $\left(400 \mathrm{MHz}, \mathrm{CD}_{2} \mathrm{Cl}_{2}\right): \delta 2.33\left(\mathrm{~s}, 6 \mathrm{H}, \mathrm{CH}_{3} \mathrm{CN}\right), 3.61$ (s, $\left.12 \mathrm{H}, \mathrm{OCH}_{3}\right) ; 4.03\left(\mathrm{~s}, 12 \mathrm{H}, \mathrm{OCH}_{3}\right) ; 6.32\left(\mathrm{~d}, 4 \mathrm{H},{ }^{4} \mathrm{~J}=2 \mathrm{~Hz}, \mathrm{H}_{\text {aryl }}\right) ; 6.58\left(\mathrm{~m}, 4 \mathrm{H}, \mathrm{H}_{\text {aryl }}\right) ; 7.14(\mathrm{~m}$, $\left.4 \mathrm{H}, \mathrm{H}_{\text {meta }}\right) ; 7.27$ (m, 2H, $\left.\mathrm{H}_{\text {para }}\right) ; 7.43\left(\mathrm{~m}, 4 \mathrm{H}, \mathrm{H}_{\text {ortho }}\right) ; 7.57\left(\mathrm{dd}, 4 \mathrm{H},{ }^{3} J(\mathrm{H}, \mathrm{H})=8 \mathrm{~Hz},{ }^{3} J(\mathrm{H}, \mathrm{H})=8\right.$ $\left.\mathrm{Hz}, \mathrm{H}_{\text {aryl }}\right) ; 8.00\left(\mathrm{~d}, 4 \mathrm{H},{ }^{3} J(\mathrm{H}, \mathrm{H})=8 \mathrm{~Hz}, \mathrm{H}_{\text {aryl }}\right) ; 9.03\left(\mathrm{~d}, 4 \mathrm{H},{ }^{3} J(\mathrm{H}, \mathrm{H})=8 \mathrm{~Hz}, \mathrm{H}_{\text {aryl }}\right) .{ }^{31} \mathrm{P}$ NMR 
(160 MHz, $\mathrm{CD}_{2} \mathrm{Cl}_{2}$ ): $\delta-3.1$ (bs). Due to solubility issues, no ${ }^{13} \mathrm{C}$ spectrum could be recorded. HRMS (ESI): $\left[\mathrm{M}-2 \mathrm{CH}_{3} \mathrm{CN}\right]^{+}$calcd for $\mathrm{C}_{76} \mathrm{H}_{54} \mathrm{O}_{8} \mathrm{P}_{2} \mathrm{Cu}: 1219.2584$, Found 1219.2523

Pd(L2)2. L2 (29 mg, $0.04 \mathrm{mmol}, 1$ eq.) was dissolved in $20 \mathrm{~mL}$ of dichloromethane. $\mathrm{PdCl}_{2}\left(\mathrm{CH}_{3} \mathrm{CN}\right)_{2}(0.04 \mathrm{mmol}, 0.5$ eq. $)$ was then added. The solution was stirred at RT for $15 \mathrm{~min}$ then the solvent was evaporated and the crude product was washed with pentane to afford $\operatorname{Pd}(\mathbf{L 2})_{2}$ as a red solid $(75 \%) .{ }^{1} \mathrm{H}$ NMR $\left(300 \mathrm{MHz}, \mathrm{CDCl}_{3}\right): \delta 0.95\left(\mathrm{t}, 12 \mathrm{H},{ }^{3} J(\mathrm{H}, \mathrm{H})=6 \mathrm{~Hz},-\right.$ $\left.\mathrm{CH}_{3}\right) ; 0.95\left(\mathrm{t}, 6 \mathrm{H},{ }^{3} J(\mathrm{H}, \mathrm{H})=6 \mathrm{~Hz},-\mathrm{CH}_{3}\right) ; 1.03\left(\mathrm{t}, 6 \mathrm{H},{ }^{3} J(\mathrm{H}, \mathrm{H})=6 \mathrm{~Hz},-\mathrm{CH}_{3}\right) 1.23-1.52(\mathrm{~m}, 40 \mathrm{H},-$ $\left.\mathrm{CH}_{2^{-}}\right) ; 1.74\left(\mathrm{~m}, 16 \mathrm{H},-\mathrm{CH}_{2^{-}}\right) ; 2.08\left(\mathrm{~m}, 8 \mathrm{H},-\mathrm{CH}_{2^{-}}\right) ; 3.92-4.31\left(\mathrm{~m}, 16 \mathrm{H}, \mathrm{O}-\mathrm{CH}_{2^{-}}\right) ; 6.39\left(\mathrm{~d}, 4 \mathrm{H},{ }^{4} \mathrm{~J}\right.$ $\left.(\mathrm{H}, \mathrm{H})=2 \mathrm{~Hz}, \mathrm{H}_{\text {aryl }}\right) ; 6.89\left(\mathrm{~m}, 4 \mathrm{H}, \mathrm{H}_{\text {meta }}\right) ; 7.07\left(\mathrm{dt}, 2 \mathrm{H},{ }^{3} J(\mathrm{H}, \mathrm{H})=8 \mathrm{~Hz}, \mathrm{H}_{\text {para }}\right) ; 7.42\left(\mathrm{dd}, 4 \mathrm{H},{ }^{3} J\right.$ $\left.(\mathrm{H}, \mathrm{H})=8 \mathrm{~Hz}, \mathrm{H}_{\text {aryl }}\right) ; 7.48-7.62\left(\mathrm{~m}, 8 \mathrm{H}, \mathrm{H}_{\text {ortho }}+\mathrm{H}_{\text {aryl }}\right) ; 7.77\left(\mathrm{~d}, 4 \mathrm{H},{ }^{3} \mathrm{~J}(\mathrm{H}, \mathrm{H})=8 \mathrm{~Hz}, \mathrm{H}_{\text {aryl }}\right) ; 9.07$ $\left(\mathrm{d}, 4 \mathrm{H},{ }^{3} \mathrm{~J}(\mathrm{H}, \mathrm{H})=8 \mathrm{~Hz}, \mathrm{H}_{\text {aryl }}\right) .{ }^{31} \mathrm{P} \mathrm{NMR}\left(162 \mathrm{MHz}, \mathrm{CDCl}_{3}\right): \delta+28.6$ (s). Due to solubility issues, no ${ }^{13} \mathrm{C}$ spectrum could be recorded. HRMS (ESI): [M-Cl] ${ }^{+}$calcd for $\mathrm{C}_{116} \mathrm{H}_{134} \mathrm{O}_{8} \mathrm{P}_{2} \mathrm{PdCl}$ : 1857.8272, Found 1857.8211.

$\operatorname{ReL}_{1} . \mathbf{L}_{\mathbf{1}}\left(30 \mathrm{mg}, 0.04 \mathrm{mmol}, 1\right.$ eq.) was refluxed in $10 \mathrm{~mL}$ of toluene with $\mathrm{Re}(\mathrm{CO})_{5} \mathrm{Cl}$ (1 eq.) for 1h. The crude solution was evaporated and the solid was washed with pentane to afford $\mathbf{1 0}$ as a red solid (60 \%). ${ }^{1} \mathrm{H}$ NMR (400 MHz, $\left.\mathrm{CDCl}_{3}\right): \delta 3.80\left(\mathrm{~s}, 6 \mathrm{H}, \mathrm{OCH}_{3}\right) ; 4.11\left(\mathrm{~s}, 6 \mathrm{H}, \mathrm{OCH}_{3}\right) ; 6.74$ (m, 2H, $\left.\mathrm{H}_{\text {aryl }}\right) ; 7.00\left(\mathrm{~m}, 2 \mathrm{H}, \mathrm{H}_{\text {aryl }}\right) ; 7.15-7.50\left(\mathrm{~m}, 3 \mathrm{H}, \mathrm{H}_{\text {meta+para }}\right) ; 7.81\left(\mathrm{dd}, 2 \mathrm{H},{ }^{3} J(\mathrm{H}, \mathrm{H})=8 \mathrm{~Hz},{ }^{3} J\right.$ $\left.(\mathrm{H}, \mathrm{H})=8 \mathrm{~Hz}, \mathrm{H}_{\text {aryl }}\right) ; 8.02\left(\mathrm{~m}, 2 \mathrm{H}, \mathrm{H}_{\text {ortho }}\right) ; 8.41\left(\mathrm{~d}, 2 \mathrm{H},{ }^{3} J(\mathrm{H}, \mathrm{H})=8 \mathrm{~Hz}, \mathrm{H}_{\text {aryl }}\right) ; 9.51\left(\mathrm{~d}, 2 \mathrm{H},{ }^{3} J\right.$ $\left.(\mathrm{H}, \mathrm{H})=8 \mathrm{~Hz}, \mathrm{H}_{\text {aryl }}\right) .{ }^{31} \mathrm{P}$ NMR $\left(162 \mathrm{MHz}, \mathrm{CDCl}_{3}\right): \delta+3.4$ (s). Due to solubility issues, no ${ }^{13} \mathrm{C}$ spectrum could be recorded. HRMS (ESI): $[\mathrm{M}]^{+}$calcd for $\mathrm{C}_{42} \mathrm{H}_{27} \mathrm{O}_{8}$ PClRe: 912.0684 , Found 912.0680.

\section{Crystal structure determination.}


X-ray crystallographic data for $\mathbf{A u}(\mathbf{L 1})_{2}$ (CCDC 861179) were previously reported. ${ }^{15}$ Single crystals of ReL1, AuL1, Cu(L1) 2 suitable for X-Ray crystal analyses were obtained by slow vapor diffusion of pentane into dichloromethane solutions. Single crystal data collection were performed at $150 \mathrm{~K}$ with an APEX II Bruker-AXS (Centre de Diffractométrie, Université de Rennes 1, France) with Mo- $K \alpha$ radiation $(\lambda=0.71073 \AA)$. Reflections were indexed, Lorentzpolarization corrected and integrated by the DENZO program of the KappaCCD software package. The data merging process was performed using the SCALEPACK program. ${ }^{30}$ Structure determinations were performed by direct methods with the solving program SIR97, ${ }^{31}$ that revealed all the non-hydrogen atoms. SHELXL program ${ }^{32}$ was used to refine the structures by full-matrix least-squares based on $F^{2}$. All non-hydrogen atoms were refined with anisotropic displacement parameters. Hydrogen atoms were included in idealized positions and refined with isotropic displacement parameters.

Single crystals of all these derivatives were always coated in paratone oil once removed from the mother solution, mounted at low temperature on the diffractometer goniometer and X-ray data collection were performed at low temperature. Atomic scattering factors for all atoms were taken from International Tables for X-ray Crystallography. ${ }^{33}$ 1487424, 1487422, 1487421, 1487423 and 861179 contain the supplementary crystallographic data for derivatives ReL1, $\operatorname{AuL1}, \mathbf{C u}(\mathbf{L} 1)_{2}$, and $\mathbf{A u}(\mathbf{L} 1)_{2}$ respectively. These data can be obtained free of charge from the Cambridge Crystallographic Data Center, 12 union Road, Cambridge CB2 1EZ, UK; Fax: (internat.) + 44-1223-336-033; E-mail: deposit@ccdc.cam.ac.uk]

\section{Density functional calculations}


B3LYP/def2-TZVP ${ }^{34}$ and CAM-B3LYP/def2-TZVP ${ }^{35}$ TD DFT calculations of the complexes were carried out at the experimentally obtained geometries (in case of the Pd complex using ligand the $\mathbf{L 1}$ instead of $\mathbf{L 2}$ ), with the Gaussian 09 suite of programs ${ }^{36}$. Geometry optimizations were carried out at the M06-2X/LANL2DZ ${ }^{37}$ and at the $\omega \mathrm{B} 97 \mathrm{X}-\mathrm{D} / \mathrm{LANL}_{2} \mathrm{DZ} \mathrm{Z}^{38}$ levels, for the $\operatorname{Pd}(\mathbf{L 1})_{2}$ complex and at the B3LYP/6-31G* level for $\mathbf{C u}(\mathbf{L 1})_{2}$ complex. In the latter case the complex with the cis and trans arranged $\mathbf{L} \mathbf{1}$ ligands was optimized. For the visualization of the Kohn-Sham MO-s the VMD program ${ }^{39}$ was used.

\section{ASSOCIATED CONTENT}

Supporting Information. "This material is available free of charge via the Internet at http://pubs.acs.org."

\section{AUTHOR INFORMATION}

\section{Corresponding Author}

*E-mail: muriel.hissler@univ-rennes1.fr

\section{Author Contributions}

The manuscript was written through contributions of all authors. All authors have given approval to the final version of the manuscript.

\section{Funding Sources}

This work is supported by the Ministère de la Recherche et de l'Enseignement Supérieur, the CNRS, the Région Bretagne, China-French associated international laboratory in "Functional Organophosphorus Materials", Balaton PHC (830386K) - FR_12_TET_A044DF3B, the French 
National Research Agency (ANR)/Research Grants Council (RGC) Joint Research Scheme (ANR MOLMAT), OTKA K 105417 and COST CM10302 (SIPS).

\section{REFERENCES AND NOTES}

(1) Watson, M. D.; Fechtenkotter, A.; Müllen, K. Chem. Rev. 2001, 101, 1267.

(2) Chen, L.; Hernandez, Y.; Feng, X.; Müllen, K. Angew. Chem. Int. Ed. 2012, 51, 7640 .

(3) Wu, J.; Pisula, W.; Müllen, K. Chem. Rev. 2007, 107, 718.

(4) Pisula, W.; Feng, X.; Müllen, K. Adv. Mater. 2010, 22, 3634.

(5) (a) Muetterties, E. L.; Bleeke, J. R.; Wucherer, E. J.; Albright, T. Chem. Rev. 1982, 82, 499. (b) Hubig, S. M.; Lindeman, S. V.; Kochi, J. K. Coord. Chem. Rev. 2000, 200$202,831$.

(6) (a) Lacoste, M.; Astruc, D. J. Chem. Soc., Chem. Commun. 1987, 667. Lacoste, M.; Rabaa, H.; Astruc, D.; Le Beuze, A.; Saillard, J. Y.; Precigoux, G.; Courseille, C.; Ardoin, N.; Bowyer, W. Organometallics 1989, 8, 2233. Schmelz, O.; Müllen, K. Chem. Eur. J. 2000, 6, 1834. (c) Herwig, P. T.; Enkelmann, V.; Woolf, A.; Chaplin, A. B. McGrady, J. E.; Alibadi, M. A. M.; Rees, N.; Draper, S.; Murphy, F.; Weller, A. S. Eur. J. Inorg. Chem. 2011, 2011, 1614 . (e) El Hamaoui, B.; Zhi, L.; Wu, J.; Li, J.; Lucas, N. T.; Tomović, Ž.; Kolb, U.; Müllen, K. Adv. Funct. Mater. 2007, 17, 1179.

(7) (a) Vecchi, P. A.; Alvarez, C. M.; Ellern, A.; Angelici, R. J.; Sygula, A.; Sygula, R.; Rabideau, P. W. Angew. Chem. Int. Ed. 2004, 43, 4497. (b) Bekyarova, E.; Sarkar, S.; Wang, F.; Itkis, M. E.; Kalinina, I.; Tian, X.; Haddon, R. C. Acc. Chem. Res. 2013, 46, 65.

(8) (a) Munakata, M.; Wu, L. P.; Kuroda-Sowa, T.; Maekawa, M.; Suenaga, Y.; Ning, G. L.; Kojima, T. J. Am. Chem. Soc. 1998, 120,8610. $\quad$ (b) Zhong, J. C.; Munakata, M.; Kuroda-Sowa, T.; Maekawa, M.; Suenaga, Y.; Konaka, H. Inorg. Chem. 2001, 40, 3191. (c) Munakata, M.; Zhong, J. C.; Kuroda-Sowa, T.; Maekawa, M.; Suenaga, Y.; Kasahara, M.; Konaka, H. Inorg. Chem. 2001, 40, $7087 . \quad$ (d) Munakata, M.; Wu, L. P.; Ning, G. L.; Kuroda-Sowa, T.; Maekawa, M.; Suenaga, Y.; Maeno, N. J. Am. Chem. Soc. 1999, 121, 4968.

(9) (a) Kim, K.-Y.; Liu, S.; Köse, M. E.; Schanze, K. S. Inorg. Chem. 2006, 45, 2509.

(b) Nolan, D.; Gil, B.; Murphy, F. A.; Draper, S. M. Eur. J. Inorg. Chem. 2011, 2011, 3248. (c) Heng, W. Y.; Hu, J.; Yip, J. H. K. Organometallics 2007, 26, $6760 . \quad$ (d) Roberts, D. J.; Gregg, D. J.; Fitchett, C. M.; Draper, S. M. Organometallics 2010, 29, 6541. (e) Roberts, D. J.; Nolan, D.; O Maille, G. M.; Watson, G. W.; Singh, A.; Ledoux-Rak, I.; Draper, S. M. Dalton Trans. 2012, 41, 8850. $\quad$ (f) El Hamaoui, B.; Laquai, F.; Baluschev, S.; Wu, J.; Müllen, K. Synth. Met. 2006, 156, 1182. (g) Elliott, A. B. S.; Horvath, R.; Sun, X.-Z.; Gardiner, M. G.; Müllen, K.; Lucas, N. T.; George, M. W.; Gordon, K. C. Inorg. Chem. 2016, 55, 4710. (h) Ibáñez, S.; Guerrero, A.; Poyatos, M.; Peris, E. Chem. Eur. J. 2015, 21, $10566 . \quad$ (i) Valdés, H.; Poyatos, M.; Peris, E. Organometallics 2015, 34, 1725. (j) Langbein, S.; Wadepohl, H.; Gade, L. H. Organometallics 2016, 35, 809. (k) Rettenmeier, C. A.; Wenz, J.; Wadepohl, H.; Gade, L. H. Inorg. Chem. 2016, 55, 8214. (l) Shchyrba, A.; Wäckerlin, C.; Nowakowski, J.; Nowakowska, S.; Björk, J.; Fatayer, S.; Girovsky, J.; Nijs, T.; Martens, S. C.; Kleibert, A.; Stöhr, M.; Ballav, N.; Jung, T. A.; Gade, L. H. J. Am. Chem. Soc. 2014, 136, 9355. 
(10) Stępień, M.; Gońka, E.; Żyła, M.; Sprutta, N. Chem. Rev. 2016, 10.1021/acs.chemrev.6b00076.

(11) (a) Draper, S. M.; Gregg, D. J.; Madathil, R. J. Am. Chem. Soc. 2002, 124, 3486.

(b) Graczyk, A.; Murphy, F. A.; Nolan, D.; Fernandez-Moreira, V.; Lundin, N. J.; Fitchett, C. M.; Draper, S. M. Dalton Trans. 2012, 41, 7746. $\quad$ (c) Brietzke, T.; Mickler, W.; Kelling, A.; Holdt, H.-J. Dalton Trans. 2012, 41, 2788. $\quad$ (d) He, B.; Dai, J.; Zherebetskyy, D.; Chen, T. L.; Zhang, B. A.; Teat, S. J.; Zhang, Q.; Wang, L.; Liu, Y. Chem. Sci. 2015, 6, 3180.

(12) (a) Saito, S.; Matsuo, K.; Yamaguchi, S. J. Am. Chem. Soc. 2012, 134, 9130.

(b) Dou, C.; Saito, S.; Matsuo, K.; Hisaki, I.; Yamaguchi, S. Angew. Chem. Int. Ed. 2012, 51, 12206. (c) Hertz, V. M.; Bolte, M.; Lerner, H.-W.; Wagner, M. Angew. Chem. Int. Ed. 2015, 54, 8800 .

(13) (a) Chen, L.; Puniredd, S. R.; Tan, Y.-Z.; Baumgarten, M.; Zschieschang, U.; Enkelmann, V.; Pisula, W.; Feng, X.; Klauk, H.; Müllen, K. J. Am. Chem. Soc. 2012, 134, 17869. (b) Martin, C. J.; Gil, B.; Perera, S. D.; Draper, S. M. Chem. Commun. 2011, 47, 3616.

(c) Gorodetsky, A. A.; Chiu, C.-Y.; Schiros, T.; Palma, M.; Cox, M.; Jia, Z.; Sattler, W.; Kymissis, I.; Steigerwald, M.; Nuckolls, C. Angew. Chem. Int. Ed. 2010, 49, 7909.

(14) (a) Wu, D.; Pisula, W.; Haberecht, M. C.; Feng, X.; Müllen, K. Org. Lett. 2009, 11, $5686 . \quad$ (b) Stassen, D.; Demitri, N.; Bonifazi, D. Angew. Chem. Int. Ed. 2016, 55, 5947.

(15) Bouit, P.-A.; Escande, A.; Szücs, R.; Szieberth, D.; Lescop, C.; Nyulászi, L.; Hissler, M.; Réau, R. J. Am. Chem. Soc. 2012, 134, 6524.

(16) (a) Draper, S. M.; Gregg, D. J.; Schofield, E. R.; Browne, W. R.; Duati, M.; Vos, J. G.; Passaniti, P. J. Am. Chem. Soc. 2004, 126, 8694. Passaniti, P.; Draper, S. M. Inorg. Chem. 2005, 44, 5654.

(17) Gregg, D. J.; Fitchett, C. M.; Draper, S. M. Chem. Commun. 2006, 3090.

(18) (a) Davis, N. K. S.; Thompson, A. L.; Anderson, H. L. Org. Lett. 2010, 12, 2124.

(b) Davis, N. K. S.; Thompson, A. L.; Anderson, H. L. J. Am. Chem. Soc. 2011, 133, 30.

(19) Fogel, Y.; Kastler, M.; Wang, Z.; Andrienko, D.; Bodwell, G. J.; Müllen, K. J. Am. Chem. Soc. 2007, 129, 11743.

(20) Riobé, F.; Szücs, R.; Bouit, P.-A.; Tondelier, D.; Geffroy, B.; Aparicio, F.; Buendia, J.; Sanchez, L.; Réau, R.; Nyulaszi, L.; Hissler, M. Chem. Eur. J 2015, 21, 6547.

(21) (a) Graule, S.; Rudolph, M.; Vanthuyne, N.; Autschbach, J.; Roussel, C.; Crassous, J.; Réau, R. J. Am. Chem. Soc. 2009, 131, 3183. (b) Fave, C.; Hissler, M.; Sénéchal, K.; Ledoux, I.; Zyss, J.; Réau, R. Chem. Commun. 2002, 1674. $\quad$ (c) Hissler, M.; Lescop, C.; Reau, R. C. R. Chim. 2008, 11, 628. (d) Nohra, B.; Yao, Y.; Lescop, C.; Réau, R. Angew. Chem. 2007, 119, 8390. $\quad$ (e) Nohra, B.; Graule, S.; Lescop, C.; Réau, R. J. Am. Chem. Soc. 2006, 128, 3520. (f) Chen, H.; Delaunay, W.; Yu, L.; Joly, D.; Wang, Z.; Li, J.; Wang, Z.; Lescop, C.; Tondelier, D.; Geffroy, B.; Duan, Z.; Hissler, M.; Mathey, F.; Réau, R. Angew. Chem. Int. Ed. 2012, 51, $214 . \quad$ (g) Leca, F.; Lescop, C.; Rodriguez-Sanz, E.; Costuas, K.; Halet, J.-F.; Réau, R. Angew. Chem. Int. Ed. 2005, 44, 4362.

$19,709$.

(22) MacDougall, J. J.; Nelson, J. H.; Mathey, F.; Mayerle, J. J. Inorg. Chem. 1980,

(23) The connectivity of this complex is supported by X-ray diffraction study, the quality of which prevent its publication. In particular, a cis-arrangement around the Pd(II) is confirmed (Figure S7). 
(24) (a) Juris, A.; Campagna, S.; Bidd, I.; Lehn, J. M.; Ziessel, R. Inorg. Chem. 1988, 27, $4007 . \quad$ (b) Schmidt, S. P.; Trogler, W. C.; Basolo, F.; Urbancic, M. A.; Shapley, J. R. In Inorg. Synth.; John Wiley \& Sons, Inc.: 2007, p 41.

(25) Mathey, F.; Fischer, J.; Nelson, J. H. Transition Metal Complexes Structures and Spectra, Structure and Bonding, 1984; Vol. 55.

(26) (a) Hissler, M.; Dyer, P. W.; Réau, R. Coord. Chem. Rev. 2003, 244, 1.

Baumgartner, T.; Réau, R. Chem. Rev. 2006, 106, 4681.

(27) CAM-B3LYP unexpectedly gives too high excitation energies for the series, including $\mathbf{L} 1$ itself - see data in the SI.

(28) The B3LYP optimization, resulted in a structure, with the two ligands being rotated away by about $30^{\circ}$, in accordance with the improper description of the dispersion effect

(29) (a) Joly, D.; Bouit, P. A.; Hissler, M. J. Mater. Chem. C 2016, 4, 3686.(b) Duffy, M. P.; Delaunay, W.; Bouit, P. A.; Hissler, M. Chem. Soc. Rev. 2016, 45, 5296.

(30) Otwinowski, Z.; Minor, W. In Methods in Enzymology, (Ed.: C.W. Carter, Jr. \& R.M. Sweet), New York:Academic Press, 1997, 276, 307.

(31) Altomare, A.; Burla, M. C.; Camalli, M.; Cascarano, G.; Giacovazzo, C.; Guagliardi, A.; Moliterni, A. G. G.; Polidori, G.; Spagna, R. J. of Applied Cryst. 1999, 32, 115.

(32) Sheldrick G.M., SHELX97, Program for the Refinement of Crystal Structures, University of Göttingen, Germany, 1997.

(33) International Tables for X-ray Crystallography, vol C, Ed. Kluwer, Dordrecht, 1992.

(34). Becke, A. D. Phys. Rev. A, 1988, 38, 3098-100; Miehlich, B.; Savin, A.;. Stoll, H Preuss, H. Chem. Phys. Lett., 1989, 157, 200-06.

(35) Yanai, T.; Tew, D.; Handy, N. Chem. Phys. Lett., 2004, 393, 51-57.

(36) Frisch, M. J.; Trucks, G. W.; Schlegel, H. B.; Scuseria, G. E.; Robb, M. A.; Cheeseman, J. R.; Scalmani, G.; Barone, V.; Mennucci, B.; Petersson, G. A.; Nakatsuji, H.; Caricato, M.; Li, X.; Hratchian, H. P.; Izmaylov, A. F.; Bloino, J.; Zheng, G.; Sonnenberg, J. L.; Hada, M.; Ehara, M.; Toyota, K.; Fukuda, R.; Hasegawa, J.; Ishida, M.; Nakajima, T.; Honda, Y.; Kitao, O.; Nakai, H.; Vreven, T.; Montgomery, J. A., Jr.; Peralta, J. E.; Ogliaro, F.; Bearpark, M.; Heyd, J. J.; Brothers, E.; Kudin, K. N.; Staroverov, V. N.; Kobayashi, R.; Normand, J.; Raghavachari, K.; Rendell, A.; Burant, J. C.; Iyengar, S. S.; Tomasi, J.; Cossi, M.; Rega, N.; Millam, J. M.; Klene, M.; Knox, J. E.; Cross, J. B.; Bakken, V.; Adamo, C.; Jaramillo, J.; Gomperts, R.; Stratmann, R. E.; Yazyev, O.; Austin, A. J.; Cammi, R.; Pomelli, C.; Ochterski, J. W.; Martin, R. L.; Morokuma, K.; Zakrzewski, V. G.; Voth, G. A.; Salvador, P.; Dannenberg, J. J.; Dapprich, S.; Daniels, A. D.; Farkas, O.; Foresman, J. B.; Ortiz, J. V.; Cioslowski, J.; Fox, D. J. Gaussian 09, revision B.01; Gaussian, Inc.: Wallingford, CT, 2010.

(37) Zhao Y, Truhlar D. G. Theor Chem Accounts 2008, 120, 215-241

(38) Chai, J. D.; Head-Gordon M Phys Chem Chem Phys 2008, 10, 6615-6620

(39) Humphrey, W., Dalke, A. and Schulten, K., J. Molec. Graphics, 1996, 14, 33-38. 
